\section{Case Reports in Dermatology}

\title{
Efficacy of a Film-Forming Medical Device Containing Piroxicam and Sun Filters in the Treatment of Multiple Actinic Keratosis Lesions in a Subject with a History of Kaposi Sarcoma
}

\author{
Elisabetta Scotti $^{\mathrm{a}} \quad$ Salvatore Deledda ${ }^{\mathrm{a}}$ Massimo Milani ${ }^{\mathrm{b}}$ \\ ${ }^{\mathrm{a} D e r m a t o l o g y}$ Clinic San Francesco Hospital ASL 3, Nuoro, Italy; ${ }^{\mathrm{b}}$ Medical Department, \\ Difa Cooper, IFC Group, Caronno Pertusella, Italy
}

\section{Keywords}

Actinic keratosis $\cdot$ Kaposi sarcoma $\cdot$ Piroxicam $\cdot$ Sunscreens

\begin{abstract}
Actinic keratosis (AK) is considered a premalignant form of skin cancer due to chronic sun exposure. In addition, human papilloma virus (HPV) has been advocated a role in the pathogenesis of this clinical condition. HPV proteins (mainly E6 and E7) seem to act synergistically with ultraviolet (UV) radiation in reducing the defensive mechanisms of keratinocyte apoptosis after UV damage. Data regarding the involvement of other viruses, i.e. human herpes viruses $(\mathrm{HHV})$, in the pathogenesis of AK are so far controversial. HHV8 is considered the infective agent involved in the development of Kaposi sarcoma. Some experimental data have shown that AK lesions carry HHV8 in more than $30 \%$ of the bioptic samples. Topical piroxicam was shown to be effective in the treatment of AK. In addition, the molecule shows antiviral action against HPV and HHV8. Here, we report the efficacy of a medical device containing a film-forming substance (polyvinyl alcohol), chemical and physical sun filters (SPF $50+$ ), and $0.8 \%$ piroxicam (Actixicam ${ }^{\mathrm{TM}}$, Difa Cooper; ACTX) in the treatment of multiple scalp AK lesions, unresponsive to other treatments, in a subject with Kaposi sarcoma and a history
\end{abstract}


of severe contact dermatitis. The subject presented with severe involvement of the scalp, with multiple hypertrophic AK lesions. Previous lesion-directed and field-targeted treatments have not been effective. The subject was treated with ACTX applied twice daily on the affected scalp. Relevant clinical improvement was observed as soon as 1 month of therapy. Complete clinical resolution of all scalp lesions was observed after 3 months of treatment. The product was well tolerated.

\section{Introduction}

Actinic keratosis (AK) is considered a premalignant form of skin cancer due to chronic sun exposure [1]. Moreover, AK is now considered a form of carcinoma in situ [2] or a form of localized squamous cell carcinoma. Chronic solar radiation is the main pathogenic factor of AK [3]. Ultraviolet B (UVB) and UVA rays cause oxidative damage and DNA alterations of keratinocytes as well as at the dermal cell level $[4,5]$. In addition, human papilloma virus (HPV) has been advocated a role in the pathogenesis of this clinical condition [6]. Experimental data available so far are compatible with a carcinogenic role of HPV in the early steps of non-melanoma skin tumor development [7]. HPV proteins (mainly E6 and E7) seem to act synergistically with UV radiation in reducing the defensive mechanisms of keratinocyte apoptosis after UV damage [8]. Data regarding the involvement of other viruses, i.e. human herpes viruses (HHV), in the pathogenesis of AK are so far controversial. HHV8 is considered the infective agent of Kaposi sarcoma [9], which is a malignancy of lymphatic endothelial cells [10]. Classic Kaposi sarcoma is quite common in the Mediterranean area [11] and in Sardinia in particular. In this Italian region, the standardized incidence of the disease is $1.58 / 100,000$ inhabitants per year, and it is more common in men than in women (2.43 vs. 0.77). Classic Kaposi sarcoma is associated with the presence of gamma herpes virus HHV8, which is commonly isolated in the histological specimens of skin lesions [12]. Some experimental data have shown that AK lesions carry HHV8 in more than $30 \%$ of the bioptic samples [13]. However, these data were not confirmed by other authors [14]. Topical piroxicam was shown to be effective in the treatment of AK [15]. In addition, the molecule could have antiviral action against HHV8 [16] and HPV [17] not related with the cyclooxygenase inhibition. In a recent study, the use of a film-forming cream containing piroxicam $0.8 \%$ and a sunscreen filter with $50+$ sun protection factor (SPF) was shown to be very effective in the treatment of AK in immunocompetent subjects [18]. Here, we report the efficacy of this filmforming medical device containing polyvinyl alcohol, chemical and physical sun filters (SPF $50+$ ), and $0.8 \%$ piroxicam (Actixicam ${ }^{\mathrm{TM}}$, Difa Cooper; ACTX) in the treatment of multiple scalp AK lesions, unresponsive to other treatments, in a subject with concomitant Kaposi sarcoma and a history of severe contact dermatitis.

\section{Case Report}

The subject, a 79-year-old man, with Fitzpatrick phototype II born in Sardinia (Italy) and with a Sardinian ancestry line, presented with a 20-year history of severe involvement of the scalp with multiple hypertrophic AK lesions (fig. 1). Previous lesion- and field-targeted treatments were no effective. Eight sessions of cryotherapy were performed in 2011. In 2012, the subject underwent methyl aminolevulinate photodynamic therapy treatment in 
three sessions and was then treated with topical diclofenac for 4 months with no clinical improvement. A diagnosis of classic Kaposi sarcoma was performed in 2008, and he was treated with oral etoposide. In 2012, the subject presented with a severe form of limb pyoderma gangrenosum, which required an oral corticosteroid treatment course. In addition, the subject reported severe allergic contact dermatitis of the hands and feet, with positive patch tests to several components (perfume mix, $p$-fenylenediamine, and Sudan yellow color).

For his AK lesions, the subject started treatment in April 2016 with ACTX applied twice daily to all the affected scalp areas. A punched biopsy of an AK lesion, performed before having started the topical treatment, in order to evaluate the presence of virus DNA with PCR methods, was positive for both HPV and HHV8. No other topical products (i.e. sunscreens) were used during the ACTX treatment period. Relevant clinical improvement was observed as soon as 1 month of therapy (fig. 2). A complete clinical resolution of all scalp lesions was observed after 3 months of treatment (fig. 3). The product was well tolerated.

\section{Discussion}

AK and non-melanoma skin cancer are very frequent skin conditions [19, 20]. Chronic sun exposure and advanced age are the most relevant risk factors in the pathogenesis of these conditions [21]. Clinical and epidemiological data available clearly demonstrated that AK is related to UV exposure and observed mostly in fair-skinned patients susceptible to solar damage [22]. Epidemiological data show that the incidence of AK development in Caucasians increases with age, proximity to the equator, and outdoor occupation [23]. AK has been recognized as a precursor of cancer or of precancerous lesions in the past; however, today, it is considered an early in situ squamous cell carcinoma [24]. The regular use of sunscreen can reduce the incidence of AK [25]. The long-term use of sunscreens in subjects with AK is now considered mandatory also after specific therapeutic lesion-directed or fieldtargeted treatments [26]. Activation of the inflammation cascade seems to play an important role in the pathogenesis of AK and non-melanoma skin cancer [27]. UVB and UVA radiation increases the expression of cyclooxygenase in the skin [28]. Anti-inflammatory agents with cyclooxygenase-inhibitory action like diclofenac [29] and piroxicam [30] in topical formulations have been shown to reduce AK lesions by 50\%. In comparison with diclofenac, piroxicam not only blocks the cyclooxygenase enzyme but also prostaglandin $E_{2}$ synthase [31]. In addition, this molecule expresses antioxidant [32] and antiviral actions [33]. Kaposi sarcoma is a malignancy of lymphatic endothelial cells. Classic Kaposi sarcoma is quite common in the Mediterranean area and in Sardinia in particular, with an incidence of 1.58/100,000 inhabitants per year [11]. It is associated with the presence of gamma herpes virus HHV8, which is commonly isolated in the bioptic specimens of the skin lesions. Some experimental data have shown that the HHV8 virus can be isolated in more than 30\% of the AK skin lesions [13]. However, these data were not confirmed by other authors [14]. In the present case report, we found that the use of a medical device containing piroxicam $0.8 \%$ and a sun filter with $50+$ SPF in a subject with multiple AK lesions of the scalp, unresponsive to previous treatment and with a history of classic Kaposi sarcoma, was very effective and well tolerated. The tested product also contains sunscreens which can be efficacious in reducing AK lesions [34] or prevent the appearance of new lesions in at-risk subjects [35]. Therefore the clinical efficacy observed in this case report may also be ascribed to this component. However, as previously discussed, an antiviral effect has been demonstrated for the piroxicam molecule, and, 
therefore, it is probable that this component of Actixicam could have been be the relevant one in this case report. If the clinical efficacy of this product, and in particular of piroxicam, can also be ascribed to an antiviral action against viral agents potentially involved in the pathogenesis of AK, like HPV or, in this particular case, HHV8, this should be specifically investigated in future studies.

\section{Statement of Ethics}

The authors state that the subject gave written informed consent to have his photographs published.

\section{Disclosure Statement}

E.S. and S.D. declare no conflicts of interest. M.M. is an employee of Difa Cooper, IFC group.

\section{References}

1 Callen JP, Bickers DR, Moy RR: Actinic keratoses. J Am Acad Dermatol 1997;36:650-653.

-2 Ackerman AB, Mones JM: Solar (actinic) keratosis is squamous cell carcinoma. Br J Dermatol 2006;155:9-22.

-3 Strickland PT, Rosenthal FS: Association of nonmelanoma skin cancer and actinic keratosis with cumulative solar ultraviolet exposure in Maryland watermen. Cancer 1990;65:2811-2817.

4 Kielbassa C, Len R, Epe B: Wavelength dependence of oxidative DNA damage induced by UV and visible light. Carcinogenesis 1997;18:811-816.

-5 Kulms D, et al: DNA damage, death receptor activation and reactive oxygen species contribute to ultraviolet radiation-induced apoptosis in an essential and independent way. Oncogene 2002;38:58445851.

6 Weissenborn SJ, et al: Human papillomavirus-DNA loads in actinic keratoses exceed those in nonmelanoma skin cancers. J Invest Dermatol 2005;125:93-97.

-7 Struijk L, et al: Markers of cutaneous human papillomavirus infection in individuals with tumor-free skin, actinic keratoses, and squamous cell carcinoma. Cancer Epidemiol Biomarkers Prev 2006;15:529535.

8 Viarisio D, et al: E6 and E7 from beta HPV38 cooperate with ultraviolet light in the development of actinic keratosis-like lesions and squamous cell carcinoma in mice. PLoS Pathog 2011;7:e1002125.

-9 Russo JJ, et al: Nucleotide sequence of the Kaposi sarcoma-associated herpesvirus (HHV8). Proc Natl Acad Sci USA 1996;93:14862-14867.

10 Fatahzadeh M: Kaposi sarcoma: review and medical management update. Oral Surg Oral Med Oral Pathol Oral Radiol 2012;113:2-16.

11 Cottoni F, De Marco R, Montesu MA: Classical Kaposi's sarcoma in north-east Sardinia: an overview from 1977 to 1991. Br J Cancer 1996;73:1132.

$\$ 12$ Cathomas G, et al: Detection of herpesvirus-like DNA by nested PCR on archival skin biopsy specimens of various forms of Kaposi sarcoma. J Clin Pathol 1996;49:631-633.

$\$ 13$ Nishimoto S, et al: Prevalence of human herpesvirus-8 in skin lesions. Br J Dermatol 1997;137:179_ 184.

14 Dupin N, et al: Lack of evidence of any association between human herpesvirus 8 and various skin tumors from both immunocompetent and immunosuppressed patients. Arch Dermatol 1997;133:537537.

15 Campione E, Diluvio L, Paterno EJ, Chimenti S: Topical treatment of actinic keratoses with piroxicam 1\% gel. Am J Clin Dermatol 2010;11:45-50.

16 Astani A, Albrecht U, Schnitzler P: Piroxicam inhibits herpes simplex virus type 1 infection in vitro. Pharmazie 2015;70:331-336.

17 Dannenberg AJ, Subbaramaiah K: US Patent No. 7,183,316. Washington, US Patent and Trademark Office, 2007. 
18 Babino G, Diluvio L, Bianchi L, Orlandi A, Di Prete M, Chimenti S, Milani M, Campione E: Long-term use of a new topical formulation containing piroxicam $0.8 \%$ and sunscreen: efficacy and tolerability on actinic keratosis. A proof of concept study. Curr Med Res Opin 2016;32:1345-1349.

19 Housman TS, Feldman SR, Williford PM, Fleischer AB, Goldman ND, Acostamadiedo JM, Chen GJ: Skin cancer is among the most costly of all cancers to treat for the Medicare population. J Am Acad Dermatol 2003;48:425-429.

Diepgen TL, Mahler V: The epidemiology of skin cancer. Br J Dermatol 2002;146:1-6.

Frost CA, Green AC: Epidemiology of solar keratoses. Br J Dermatol 1994;131:455-464. Moy R: Clinical presentation of actinic keratoses and squamous cell carcinoma. J Am Acad Dermatol 2000;42:S8-S10.

Gloster HM, Brodland DG: The epidemiology of skin cancer. Dermatol Surg 1996;22:217-226. Röwert-Huber J, Patel MJ, Forschner T, Ulrich C, Eberle J, Kerl H, Stockfleth E: Actinic keratosis is an early in situ squamous cell carcinoma: a proposal for reclassification. Br J Dermatol 2007;56:8-12. Thompson SC, Jolley D, Marks R: Reduction of solar keratoses by regular sunscreen use. N Engl J Med 1993;329:1147-1151.

26 De Berker D, McGregor JM, Hughes BR: Guidelines for the management of actinic keratoses. Br J Dermatol 2007;156:222-230.

Thornfeldt CR: Chronic inflammation is etiology of extrinsic aging. J Cosmet Dermatol 2008;7:78-82. Isoherranen K, Punnonen K, Jansen C, Uotila P: Ultraviolet irradiation induces cyclooxygenase-2 expression in keratinocytes. Br J Dermatol 1999;140:1017-1022.

29 Nelson C, Rigel D, Smith S, Swanson N, Wolf J: Phase IV, open-label assessment of the treatment of actinic keratosis with 3.0\% diclofenac sodium topical gel (Solaraze). J Drugs Dermatol 2003;3:401-407.

-30 Samrao A, Cockerell CJ: Pharmacotherapeutic management of actinic keratosis: focus on newer topical agents. Am J Clin Dermatol 2013;14:273-277.

-31 Morham SG, Langenbach R, Loftin CD, Tiano HF, Vouloumanos N, Jennette JC, Smithies O: Prostaglandin synthase 2 gene disruption causes severe renal pathology in the mouse. Cell 1995;83:473-482.

-32 Bartosiewicz G, Mezes M, Nemet J: Changes in lipid, peroxide, and anti-oxidant blood levels during piroxicam (Hotemin) treatment. Ther Hung 1992;41:67-71.

33 Guilford JM, Pezzuto JM: Natural products as inhibitors of carcinogenesis. Expert Opin Investig Drugs 2008;17:1341-1352.

34 Naylor MF, Boyd A, Smith DW, Cameron GS, Hubbard D, Neldner KH: High sun protection factor sunscreens in the suppression of actinic neoplasia. Arch Dermatol 1995;131:170-175.

35 Ulrich C, Jürgensen JS, Degen A, et al: Prevention of non-melanoma skin cancer in organ transplant patients by regular use of a sunscreen: a 24 months, prospective, case-control study. Br J Dermatol 2009;161:78-84. 


\section{Case Reports in Dermatology}

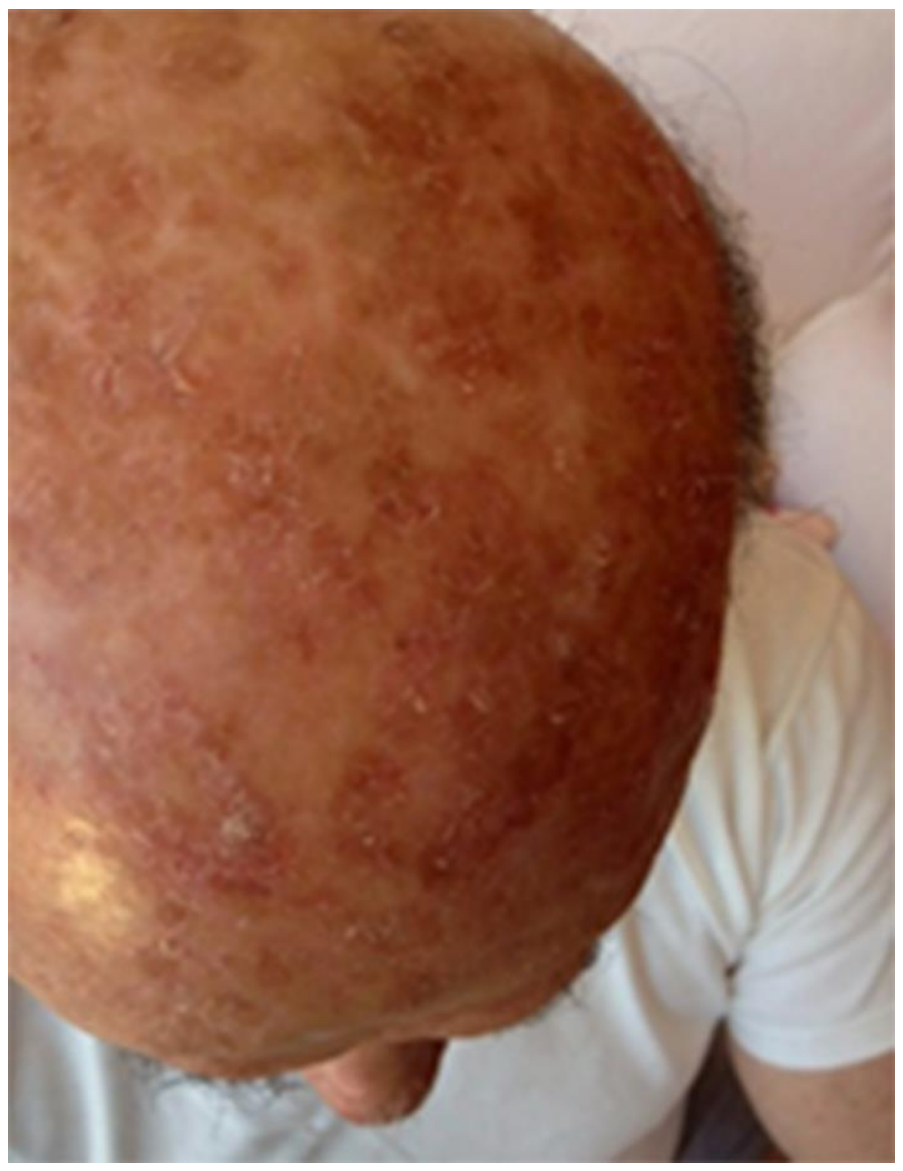

Fig. 1. Baseline condition. 


\section{Case Reports in Dermatology}

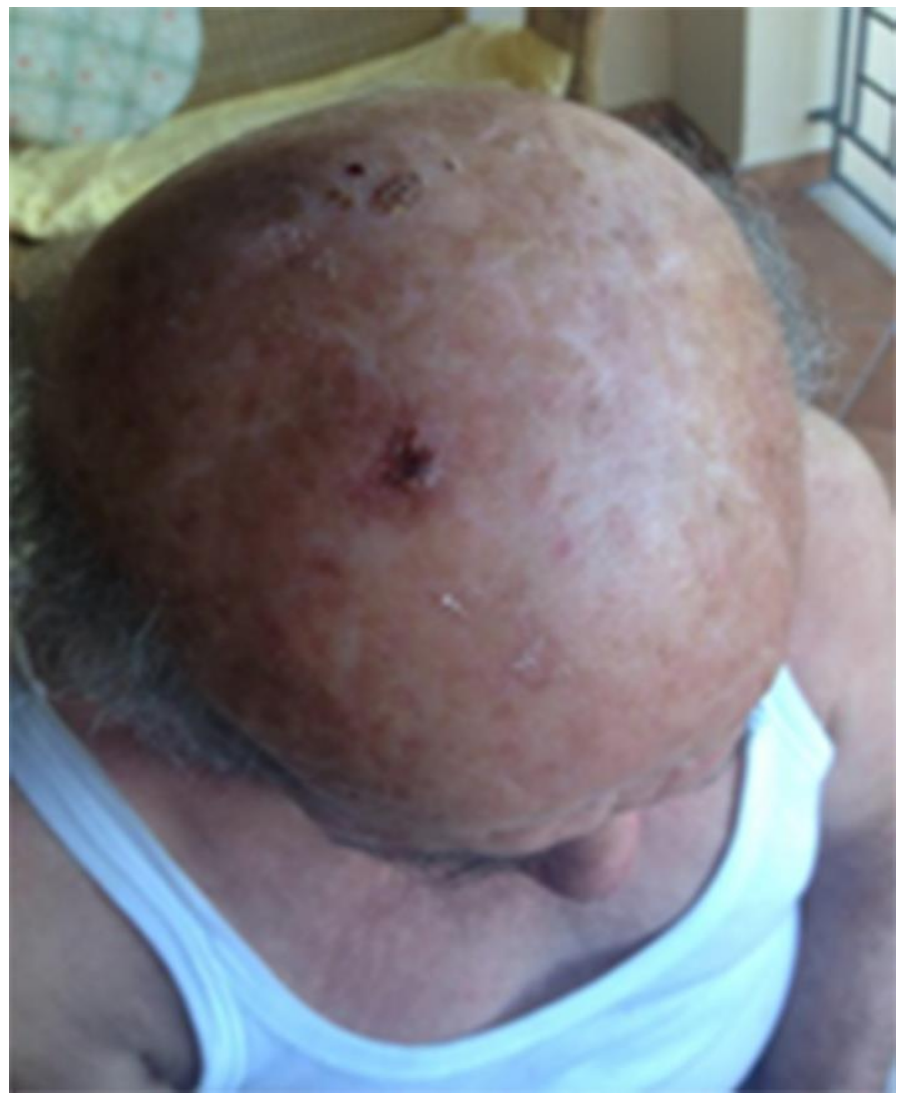

Fig. 2. After 1 month of ACTX treatment.

Scotti et al: Efficacy of a Film-Forming Medical Device Containing Piroxicam and Sun Filters in the Treatment of AK Lesions in a Subject with a History of Kaposi Sarcoma 


\section{Case Reports in Dermatology}

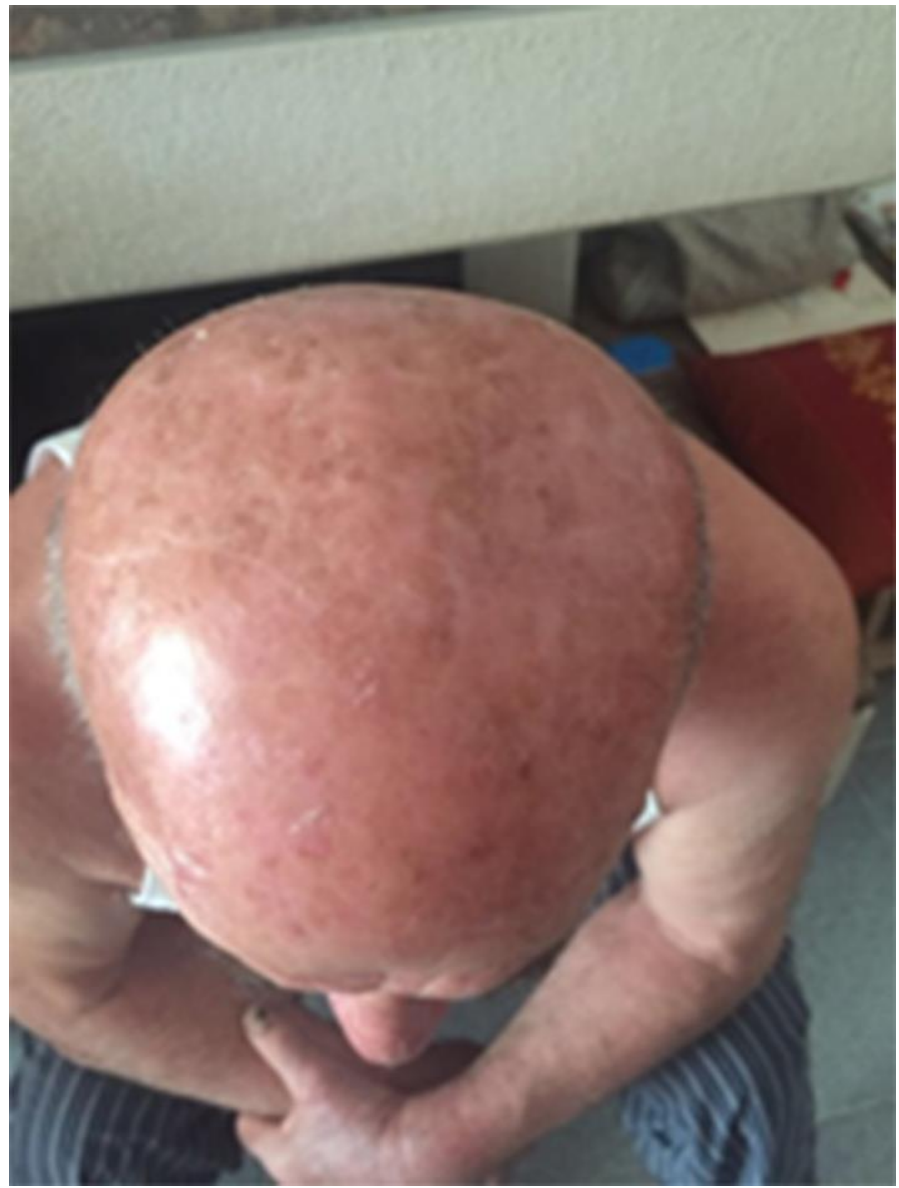

Fig. 3. After 3 months of ACTX treatment. 